\title{
Drought, heat, and their combined stress reduce the productivity and alter the photosynthetic characteristics of different alpine meadow plants
}

\author{
Li Ma ${ }^{1}$, Zhonghua Zhang ${ }^{1}$, Bingrong Zhou ${ }^{1}$, Manhou Xu${ }^{1}$, and H Zhou ${ }^{2}$ \\ ${ }^{1}$ Affiliation not available \\ ${ }^{2}$ Northwest Plateau Institute of Biology, Chinese Academy of Sciences
}

September 11, 2020

\begin{abstract}
Alpine meadow plants, which are adapted to humid and cold environments, are more sensitive to environmental factors such as drought and high temperatures. However, excluding species competition, the physiological responses of individual alpine meadow species to drought and heat stress remain unclear. In this study, four representative species of typical functional groups in an alpine meadow of the Qinghai-Tibet Plateau were selected as experimental materials. Heat (H1, H2), drought (D1, D2), and combined heat and drought stress (D1H1, D2H2) treatments were implemented to reveal the physiological characteristics' response to a constant drought and heat environment. Our results showed that the leaf water content (LWC) of Kobresia humilis and Poa annua increased significantly under heat stress and the compound heat and drought stress $(\mathrm{P}<0.05)$. Additionally, the aboveground biomass (AGB) of Oxytropis ochrocephala and Saussurea pulchra decreased significantly under compound stress $(\mathrm{P}<0.05)$. The response patterns of the net photosynthetic rate $(\mathrm{Pn})$ and transpiration rate $(\mathrm{Tr})$ of $\mathrm{K}$. humilis and $\mathrm{P}$. annua under various stress treatments were similar; as were those of O. ochrocephala and S. pulchra. The stomatal conductance (Gs) variation in K. humilis, P. annua, O. ochrocephala, and S. pulchra were the same under three kinds of stress treatments. The photosynthetic characteristics were more sensitive to the effects of composite than of single factors. The drought $\times$ heat $\times$ species treatment had a significant influence on various indexes except on height and the belowground biomass $(\mathrm{P}<0.01)$. Within a certain range, daytime temperature (DT) promoted the height and increased the LWC of the plants, while it inhibited their AGB and intercellular CO2 concentration. The Pn, Tr, and Gs were more sensitive to soil moisture than to DT. Our results help improve understanding of the physiological response regularity of representative alpine meadow plant species to continuous drought and high temperature conditions.
\end{abstract}

\section{Drought, heat, and their combined stress reduce the productivity and alter the photosynthetic characteristics of different alpine meadow plants}

Li Ma ${ }^{1,4}$, Zhonghua Zhang ${ }^{1,4}$, Bingrong Zhou ${ }^{2}$, Manhou Xu ${ }^{3}$, Huakun Zhou ${ }^{1}$

$\left({ }^{1}\right.$ Northwest Plateau Institute of Biology, Chinese Academy of Sciences, Key Laboratory of Cold Regions Restoration Ecology, Xining, Qinghai Province 810008, China; ${ }^{2}$ The Qinghai Institute of Meteorological Science, Xining, Qinghai Province 810001, China; ${ }^{3}$ Taiyuan Normal University, Jinzhong, Shanxi Province 030619, China ; ${ }^{4}$ University of Chinese Academy of Sciences, Beijing 100049, China)

Correspondence: Huakun Zhou, Northwest Institute of Plateau Biology, Chinese Academy of Sciences, Xining, China. Emails: hkzhou@nwipb.cas.cn

Abstract: Alpine meadow plants, which are adapted to humid and cold environments, are more sensitive to environmental factors such as drought and high temperatures. However, excluding species competition, the physiological responses of individual alpine meadow species to drought and heat stress remain unclear. 
In this study, four representative species of typical functional groups in an alpine meadow of the QinghaiTibet Plateau were selected as experimental materials. Heat (H1, H2), drought (D1, D2), and combined heat and drought stress (D1H1, D2H2) treatments were implemented to reveal the physiological characteristics' response to a constant drought and heat environment. Our results showed that the leaf water content (LWC) of Kobresia humilis and Poa annua increased significantly under heat stress and the compound heat and drought stress $(P<0.05)$. Additionally, the aboveground biomass (AGB) of Oxytropis ochrocephala and Saussurea pulchra decreased significantly under compound stress $(P<0.05)$. The response patterns of the net photosynthetic rate $(\mathrm{Pn})$ and transpiration rate $(\mathrm{Tr})$ of $K$. humilis and $P$. annua under various stress treatments were similar; as were those of $O$. ochrocephala and $S$. pulchra. The stomatal conductance (Gs) variation in $K$. humilis, $P$. annua, $O$. ochrocephala, and $S$. pulchra were the same under three kinds of stress treatments. The photosynthetic characteristics were more sensitive to the effects of composite than of single factors. The drought $\times$ heat $\times$ species treatment had a significant influence on various indexes except on height and the belowground biomass $(P<0.01)$. Within a certain range, daytime temperature (DT) promoted the height and increased the LWC of the plants, while it inhibited their AGB and intercellular $\mathrm{CO}_{2}$ concentration. The $\mathrm{Pn}$, Tr, and Gs were more sensitive to soil moisture than to DT. Our results help improve understanding of the physiological response regularity of representative alpine meadow plant species to continuous drought and high temperature conditions.

Keywords: alpine meadow, drought stress, heat stress, productivity, photosynthetic characteristics

\section{INTRODUCTION}

In the process of growth and development, plants often suffer from the stress imposed by biotic and abiotic factors (Salvucci et al., 2004). Among the latter, high temperature and drought are the main environmental factors that limit the growth and productivity of various plants (Sita et al., 2017). The fifth assessment report of the Intergovernmental Panel on Climate Change (IPCC) points out that global warming is an indisputable fact and the global temperature is predicted to rise by $1.8-4$ by the end of the $21^{\text {st }}$ century (Pachauri et al., 2014). Recent climate change models predict that the frequency and duration of periods of high temperatures and moisture deficits are on the rise, especially for extreme climatic events (Chen et al., 2010); for instance, high temperatures are accompanied by exceptional drought in some regions (Field et al., 2012). These harsh climates cause changes in the physiological and ecological processes of plants in the region, hinder plant growth and development (Allen et al., 2010), and seriously affect plant distribution and productivity. It follows that such climates have become important environmental factors affecting plant growth and development (Song et al., 2018). Recent studies have revealed that the response of plants to a combination of different abiotic stresses is unique and cannot be directly extrapolated from the response of plants to each of the different stresses applied individually (Ahmed et al., 2013). This emphasizes the necessity to study the vegetation response of terrestrial ecosystems to drought, high temperature, and their combined stress, which have become the focus of research in recent years (Mahalingam, 2015; Zandalinas et al., 2017; Lawas et al., 2018).

The co-occurrence of drought and high temperature is more harmful to plant growth than the single influence of one of these factors (Nankishore \& Farrell, 2016; Sehgal et al., 2019). The response of the photosynthetic parameters of plant leaves and plant productivity to high temperatures and drought reflect the light energy utilization efficiency and growth rate of the plant photosynthetic system. Research has shown that when heat and drought stress co-occur, they initiate various processes, such as the accumulation of large amounts of harmful substances in plants, a decreased photosynthetic rate by changing the activity of various enzymes involved in plant photosynthesis and metabolism coupled with abnormal respiration, closed stomata, high leaf temperature, and reduced water use efficiency in plants (Hao et al., 2019; Qaseem et al., 2019). Furthermore, various studies have demonstrated that the impact of heat and drought stress on plant growth, yield, and physiology varies among different crops (Bakhshandeh et al., 2019), which is also related to the different characteristics of each species. The effects on yield or any other trait may be synergistic, antagonistic, or hypo-additive (Pradhan et al., 2012; Prasad et al., 2011).

The effects of the global climate change are most visible on the physiological and ecological processes of 
plants in high latitudes and altitudes, owing to the faster temperature rise in these regions (Penuelas et al., 2013; Li et al., 2018). Kobresia humilis, Poa annua, Oxytropis ochrocephala, and Saussurea pulchra are typical representative functional group Sedge, Graminoid, Legume, and Forb species, respectively, in a $K$. humilis meadow, and are also key plant species related to the stability of alpine grassland ecosystems (Ren et al., 2013; Zhao et al., 2015). These plants, which adapted to living in cold, humid plateau climates long ago, are more sensitive to the combined effects of drought and heat caused by global climate change. The existing research on the combined effects of high temperature and drought mainly focuses on herbaceous ground covers (Song et al., 2018), arbor forest species (Huang et al., 2011; Read et al., 2014), and crops such as rice (Lawas et al., 2019), wheat (Pradhan et al., 2012), and lentils and their seeds (Sita et al., 2017; Sehgal et al., 2019). However, there are relatively few studies on alpine grassland plant species distributed in the Qinghai-Tibet Plateau. Moreover, in some studies, it proved difficult to control the environmental factors accurately in field experiments, while their applicability was poor (Zhang et al., 2010; Yu et al., 2015), owing to a lack of research data on the physiological ecology of individual alpine meadow species under the influence of drought and high temperature or their combined effects.

As there are relatively few indoor studies on the physiological and ecological response and adaptation strategies of alpine meadow plants, our research objects in this study were typical alpine meadow plants $(K$. humilis, P. annua, O. ochrocephala, and S. pulchra ). These were subjected to drought, heat, and the combined stress of the two in an artificial climate chamber, with the aim of revealing the physiological response of alpine meadow species to continuous environmental stress. More specifically, the present study aimed:

(1) To evaluate the effects of drought, heat, and their combined stress on the productivity and photosynthetic characteristics of four different alpine meadow species under a controlled environment.

(2) To detect differences in the performance of different alpine meadow species under heat, drought, and their interaction.

(3) To explore the dominant environmental factors that affect the response of different alpine meadow plants under drought, heat, and their interaction.

Our results can provide a theoretical basis for the rational utilization of grassland resources in alpine regions under the threat of climate change.

\section{MATERIALS AND METHODS}

\subsection{Plant materials}

All species (K. humilis, P. annua, O. ochrocephala, and S. pulchra) were obtained from a natural K. humilis meadow of Haibei National Field Research Station of Alpine Grassland Ecosystem (37deg29' N-37'45 'N, 101deg12' E-101deg23' E; altitude 3,280 m). The average annual precipitation, air temperature, and sunshine duration of the area were $560 \mathrm{~mm},-1.7 \mathrm{degC}$, and 2,462.7 h, respectively. The soil in the alpine meadow is classified as Mat-Gryic Cambisol, and it is rich in organic matter. The main vegetation types in this region and on the Tibetan Plateau consist of K. humilis and K. pymaeameadows (Du et al., 2020).

Approximately one month after the plants turned green, on June 4, 2019, we collected samples for the experiments. We selected plants with good and consistent growth. The soil volume with an area of plant largest projected on the ground and a height of $10 \mathrm{~cm}$ underground as the sampling standard. The samples were then packed in envelope bags and brought back to the laboratory. Thirty plants of each species (a total of 120 plants from all four species) were sampled. In order to avoid irreversible man-made damage to the grassland, the distance between each collected plant sample was not less than $5 \mathrm{~m}$.

\subsection{Experimental and treatment conditions}

The preculture as well as the drought, heat, and combined drought and heat treatments, were carried out in three artificial climate chambers (AI000, Canada).

1. Preculture (June 5-12, 2019): The plants were acclimated to the growth chamber for seven days 
before being subjected to the treatments. Plant samples collected in the field were transplanted into an experimental pot with an inner diameter of $8 \mathrm{~cm}$ and a height of $10 \mathrm{~cm}$. Then, the samples were placed into an artificial intelligence climate box, where the daytime and night temperatures were 18.5 and 4 , respectively, and the air humidity was $60 \%$; they were watered once every $2 \mathrm{~d}$, with the water quantity being $100 \%$ of the moisture evaporation (ET) (the necessary water quantity was weighed). The preculture lasted $7 \mathrm{~d}$; then, in order to ensure a survival rate, dead plants were removed, and 27 basins with plants of the same size and similar growth rate were selected for each of the four species, totaling 108 basins, to be used in the treatment experiment.

2. Stress treatment (June 13-July 13, 2019): Two drought gradients (D1, D2), two heat gradients (H1, H2), two drought and heat compound treatment gradients (D1H1, D2H2), and a control (CK) treatment were established in the experiment(Table 1). Each treatment was performed in triplicate.

CK, D1, D2: The day and night temperature were set at $18.5 \mathrm{degC}$ and $4 \mathrm{degC}$, respectively. The plants were watered every two days for $100 \%$ ET. D1 and D2 were treated at the same temperature as CK and watered once every two days (at 8:00 a.m. every day). The watering amount was reduced to $50 \%$ ET for D1 and $20 \%$ ET for D2. A total of 36 samples (3 treatments x 4 species x 3 replicates) were placed in the same incubator.H1, D1H1: The day and night temperatures were set at $21.5 \operatorname{deg} \mathrm{C}$ and $7 \mathrm{degC}$, respectively, in H1. The plants were watered every two days for $100 \%$ ET. A total of 24 samples $(2$ treatments x 4 species $\mathrm{x} 3$ replicates) were placed in the same incubator at the same time D1 was processed.H2, D2H2: The day and night temperatures were set at $24.5 \mathrm{degC}$ and $10 \mathrm{degC}$, respectively, in H2. The plants were watered every two days for 100\% ET. A total of 24 samples (2 treatments x 4 species x 3 replicates) were placed in the same incubator at the same time D2 was processed.

\subsection{Determination index and method}

1) Photosynthetic traits: After the experiment, at 10:00 pm on July 12, 2019, we selected 2-3 mature leaves from the same node of each plant to measure their physiological traits with a Li-Cor 6400 Portable Photosynthesis system (LI-6800, USA). The main observed photosynthetic characteristic indexes were net photosynthetic rate $(\mathrm{Pn})$, transpiration rate $(\mathrm{Tr})$, stomatal conductance $(\mathrm{Gs})$, and intercellular $\mathrm{CO}_{2}$ concentration $(\mathrm{Ci})$. The following conditions were maintained during the measurements: $\mathrm{CO}_{2}$ concentration: $360-400 \mu \mathrm{mol} \cdot \mathrm{mol}^{-1}$; flow rate: $500 \mu \mathrm{mol} \cdot \mathrm{s}^{-1}$; leaf temperature: $23 \pm 0.4{ }^{\circ} \mathrm{C}$; relative humidity: $60 \pm 5 \%$; light illumination: $750 \mu \mathrm{mol} . \mathrm{m}^{-2} \cdot \mathrm{s}^{-1}$.

2) Water use efficiency (WUE): The WUE was recorded using the following formula (Pn and Tr were defined in the previous section):

$$
W U E=P_{n} / T_{r}
$$

3) Leaf water content (LWC): This was obtained by a conventional weighing method.

At the end of the experiment, the leaves of the four species were removed and they were kept in an oven at $80{ }^{\circ} \mathrm{C}$ for $24 \mathrm{~h}$ to record their dry weight. The LWC was recorded using the following formula:

$$
L W C=\left(\frac{W_{\text {fresh }}-W_{\text {dry }}}{W_{\text {fresh }}}\right) \times 100 \%
$$

4) Aboveground and belowground biomass (AGB and BGB): After the determination of photosynthetic traits, the aboveground branches and leaves of the plants were separated from the underground roots, and the roots and soil were separated and washed clean with a 60 target quasi-soil screen $(0.28 \mathrm{~mm}$ aperture). Finally, the aboveground and underground parts were placed in an oven at $65{ }^{\circ} \mathrm{C}$ and dried to constant weight. The ABG and BGB of the plants was obtained by weighing them with an electronic balance with an accuracy of $0.001 \mathrm{~g}$.

\subsection{Data Analysis}


The significant differences among the treatments were analyzed using analysis of variance (ANOVA) in a factorial design. A three-factor ANOVA on the influence of species, drought, and high temperature was conducted in IBM SPSS Statistics for Windows, version 24.0 (IBM Corp., Armonk, NY, USA). The trend chart of different indicators under different treatments was created in Origin 8.0. Canoco 4.5 was used for detrended correspondence analysis (DCA) and redundancy analysis (RDA). The data in the figures are represented as the mean \pm standard error.

\section{RESULTS}

\subsection{Height and LWC}

The height of $O$. ochrocephala decreased significantly under drought stress compared with that of the CK (40.93\% and $60.76 \%$ under the D1 and D2 treatments, respectively) $(P<0.05)$. The heights of K. humilis, $P$. annua, and $S$. pulchra increased by $51.72 \%, 132.92 \%$, and $137.35 \%$ respectively, under the $\mathrm{H} 2$ treatment $(P<0.05)$, while that of $O$. ochrocephaladecreased significantly $(45.15 \%)(P<0.05)$. The heights of $K$. humilis and S. pulchra increased significantly under the D2H2 treatment (75.42\% and $81.93 \%$, respectively) $(P<0.05)$ (Figure 1).

The LWC of K. humilis, P. annua, and S. pulchra decreased significantly $(39.75 \%, 28.12 \%$, and $37.48 \%$, respectively) under the D2 treatment. The LWC of $K$. humilis and $P$. annua increased significantly $(P$ $<0.05)$ under the high temperature and the combined stress owing to the interaction of drought and heat. The LWC of $S$. pulchra increased significantly only under the $\mathrm{H} 2$ and D2H2 treatments $(P<0.05)$. The LWC change of $O$. ochrocephala was non-significant in all treatments $(P>0.05)$. Drought inhibited the LWC of K. humilis, $P$. annua, and S. pulchra, while high temperature and the compound stress of drought and heat promoted an increase in the moisture content of the leaves (Table 2).

\subsection{Aboveground and belowground biomass}

The AGB of $K$. humilis decreased significantly under the $\mathrm{H} 2$ treatment $(72.66 \%)(P<0.05)$. Its BGB increased significantly under the D2H2 treatment $(98.13 \%)$ and decreased significantly under the $\mathrm{H} 2$ treatment $(35.68 \%)(P<0.05)$. The AGB of $P$. annua decreased significantly under the D1H1 treatment $(79.84 \%)(P$ $<0.05)$ and increased slightly, but not significantly $(P>0.05)$, under the D2 treatment $(14.48 \%)$. The BGB change of $P$. annua was not significant for all treatments.

The AGB of $O$. ochrocephala and S. pulchra decreased with the high temperature and drought stress increase, as well as under the compound heat and drought stress. The AGB of O. ochrocephaladecreased significantly under the $\mathrm{H} 2, \mathrm{D} 1 \mathrm{H} 1$, and $\mathrm{D} 2 \mathrm{H} 2$ treatments $(86.95 \%, 73.65 \%$, and $87.95 \%$, respectively $)(P<0.05)$. The AGB of $S$. pulchra decreased the most under the D2H2 treatment (95.50\%). The BGB of O. ochrocephala and S. pulchraincreased gradually with the increase of high temperature stress, and decreased with the increase of the compound heat and drought stress; the BGB of both species decreased significantly under the D2H2 treatment $(55.47 \%$ and $34.42 \%$, respectively) $(P<0.05)$ (Figure 2$)$.

\subsection{Photosynthetic traits}

The Pn of K. humilis and P. annua decreased significantly with the drought stress $(84.16 \%$ and $87.36 \%$, respectively, under the D2 treatment) and combined drought and heat stress increase $(51.71 \%$ and $60.95 \%$, respectively, under the $\mathrm{D} 2 \mathrm{H} 2$ treatment $)(P<0.05)$. After the drought and high temperature stress, the Pn was maintained at a low level of $0.52-0.81 \mu \mathrm{mol} \cdot \mathrm{m}^{-2} \cdot \mathrm{s}^{-1}$ and a relatively high level of $4.70-4.84 \mu \mathrm{mol} \cdot \mathrm{m}^{-2} \cdot \mathrm{s}^{-1}$, respectively. The Pn of $O$. ochrocephala and $S$. pulchra decreased significantly under both the drought and the combined drought and heat stress $(P<0.05)$. The Pn of $S$. pulchra first increased significantly $(12.16 \%$ under the $\mathrm{H} 1$ treatment) and then decreased significantly $(71.19 \%$ under the $\mathrm{H} 2$ treatment $)(P<0.05)$ with the increase of the high temperature stress; the Pn of $O$. ochrocephala changed in a similar manner(Figure $3 \mathrm{~A})$.

The $\operatorname{Tr}$ of $K$. humilis and P. annua decreased significantly under drought stress $(63.10 \%$ and $69.20 \%$, respectively, under the D2 treatment). The Tr of the same species decreased significantly under the H1 
treatment (46.53\% and $24.37 \%$, respectively) and increased under the $\mathrm{H} 2$ treatment $(20.80 \%$ and $25.55 \%$, respectively). The $\operatorname{Tr}$ characteristics of $O$. ochrocephala under different stress conditions were consistent with those of S. pulchra; the drought and high temperature stress increase resulted in a significant $\operatorname{Tr}$ decrease (69.87\% and $69.10 \%$, respectively, under the D2 treatment; $63.95 \%$ and $64.40 \%$, respectively, under the $\mathrm{H} 2$ treatment) $(P<0.05)$, as this remained at a relatively low level of $4.70-4.84 \mu \mathrm{mol} \cdot \mathrm{m}^{-2} \cdot \mathrm{s}^{-1}$. An increase in the compound drought and heat stress, initially resulted in a decrease and then in an increase in the Tr, which reached a significant level in $S$. pulchra $(P<0.05)$ (Figure 3B).

The Gs variation of $K$. humilis and $P$. annua was the same under the three treatments, as it initially increased and then decreased with the stress increase. The Gs decrease of $K$. humiliswas higher than its Gs increase $(P<0.05)$, while the opposite was true for the Gs of $P$. annua. The Gs variation of $O$. ochrocephala was the same under the three treatments, as it initially increased and then decreased with the stress increase; Gs was more sensitive under the D1, H1, and D1H1 treatments (it increased by $95.88 \%, 288.00 \%$, and $112.93 \%$, respectively) $(P<0.05)$. The Gs of $S$. pulchra showed a significantly decreasing trend under different treatments $(68.79 \%, 78.44 \%$, and $78.63 \%$ under the $\mathrm{D} 2, \mathrm{H} 2$, and $\mathrm{D} 2 \mathrm{H} 2$ treatments, respectively $)(P<0.05)$ (Figure 3C).

The $\mathrm{Ci}$ of $K$. humilis showed a decreasing trend under the stress treatments and it decreased significantly (by $49.30 \%)$ under the D2H2 treatment $(P<0.05)$. The $\mathrm{Ci}$ of $P$. annuafirst decreased and then increased with the stress increase. The $\mathrm{Ci}$ in this species decreased more under the D1 and $\mathrm{H} 1$ treatments $(26.36 \%$ and $24.57 \%$, respectively) than under the D1H1 treatment $(8.58 \%)(P<0.05)$. The Ci of O. ochrocephala decreased significantly under high temperature stress $(20.11 \%$ and $46.29 \%$ under the $\mathrm{H} 1$ and $\mathrm{H} 22$ treatment, respectively) $(P<0.05)$, and maintained a higher level of $330.72 \mu \mathrm{mol} / \mathrm{mol}$ under drought stress. The Ci of $S$. pulchra did not change in a consistent manner as a response to the stress treatments. Under compound stress, the $\mathrm{Ci}$ of $S$. pulchra decreased significantly $(21.45 \%$ under the D1H1 treatment) $(P<0.05)$ (Figure $3 \mathrm{D})$.

\subsection{Correlation analysis among characteristic indexes}

The correlation analysis of eight height indicators, LWC, AGB, BGB, and four photosynthetic characteristic indexes showed that there was a significant positive correlation between height and AGB, with a correlation coefficient of $0.383(P<0.01)$, and a negative but not significant correlation with BGB. LWC was negatively correlated with AGB and $\mathrm{Ci}$, with correlation coefficients of -0.472 and -0.280 , respectively $(P<0.01)$, and had a significantly positive correlation with $\mathrm{Pn}(P<0.05)$. Pn had a significantly positive correlation with Tr and Gs, with correlation coefficients of 0.384 and 0.373 , respectively $(P<0.01)$. Tr had a significantly positive correlation with Gs and $\mathrm{Ci}(P<0.01)$, with correlation coefficients of 0.426 and 0.349 , respectively. Finally, Gs and Ci had a significantly positive correlation, with a correlation coefficient of $0.380(P<0.01)$ (Table 3).

\subsection{Three-way ANOVA analysis}

The output of the three-way ANOVA indicated significant effects of the heat, drought, and the combined heat and drought treatments on eight characteristic indexes in the four alpine meadow species. Height was significantly affected by species $(P<0.05)$ and heat $(P<0.01)$. The LWC and AGB were significantly affected by the height, species, drought and heat interaction, and drought, heat, and species interaction $(P<0.01)$. The LWC was relatively weakly affected by drought $(P<0.05)$. The effect of six of the seven treatments on BGB was non-significant.. Except for species, Pn was significantly affected by the other single and compound factors $(P<0.01)$. The effect of compound factors was more significant than that of single factors on $\operatorname{Tr}(P<0.01)$. Except for height and the drought and height interaction, Gs was significantly affected by the other single and compound factors $(P<0.01)$. Ci was significantly affected by seven factors, with the species, drought and species interaction, height and species interaction, and drought, height, and species interaction having extremely significant effects $(P<0.01)$ (Table 4$)$.

\subsection{Redundancy analysis}


We used DCA and RDA to analyze the relationship between species characteristics and environmental factors. The plant data were sorted by DCA, and the gradient lengths of the four sorting axes were obtained, of which the maximum value was $0.63<3$; therefore, we selected the RDA method. The eigenvalues of the sorting axis and the cumulative interpretation showed that daytime temperature (DT), nighttime temperature (NT), and soil moisture condition (SM) explained $35.70 \%$ of the plant change variation. The first two axes explained $35.70 \%$ of the plant change variation and $100 \%$ of the species-environment relationship variation. The results could explain all the variation in the species-environment relationship (Table 5).

Within a certain range, the SM had the greatest influence on the characteristic indexes of species, followed by DT, and NT, which exerted the least influence on the change of the characteristic plant indexes (Figure 4). All vegetation characteristic indexes were positively correlated with SM, which had the greatest impact on Pn and WUE $(P<0.01)$ and the least impact on BGB, followed by Tr, Gs, and LWC, which had a significantly positive correlation with SM $(P<0.05)$. Daytime temperature exerted the greatest positive influence on LWC and $\mathrm{H}$, as it had an extremely significant positive correlation with both $(P<0.01)$, and the least influence on Pn. Daytime temperature exerted the greatest negative influence on AGB and Gs, as it had a very significant negative correlation with these parameters $(P<0.01)$, and the least influence on $\mathrm{Ci}$ (Table 6).

\section{DISCUSSION}

Several organisms gradually demonstrate adaptive changes in their morphological and physiological characteristics and the greatest plastic response (heat resistance and drought resistance) under continuous drought and high temperature stress (Seki et al., 2007; An \& Liang, 2012). However, the amount of drought and high temperature stress that species can withstand differ (Li \& Li, 2016; Pradhan et al., 2012); more specifically, alpine meadow plants grown in low-temperature restricted environments are extremely sensitive to temperature and drought

Leaves, the main function of which is photosynthesis, are the most flexible and sensitive plant organs to environmental stress (Xue et al., 2012). Drought or high temperature stress will generally reduce the LWC (Zhang et al., 2020). The results of the present study showed that drought stress and high temperature stress decreased and increased the LWC, respectively. The LWC was more affected by drought stress than by heat; these results corroborate those of Keyvan (2010). The LWC ofK. humilis and P. annua increased under high temperature stress, decreased significantly under excessive drought, and increased significantly under the compound heat and drought stress, thereby indicating that temperature played a key role in the effect of the compound stress on LWC. The LWC change of $S$. pulchra demonstrate that it is sensitive to both excessive heat and the excessive combined stress, which is consistent with the research results of Zhang et al. (2020). Excessively high temperature and drought destroy the photosynthetic mechanism of mesophyll cells in plant leaves, cause irreversible damage, reduce the LWC of plants, and result in yellowing (Zandalinas et al., 2017). The different responses of the four plant species to drought and high temperature stress in terms of their LWC changes, indicate that different plant characteristics play an important role in a species' response mode.

High temperatures can increase the consumption of organic matter by plant respiration in order to reduce the biomass or promote organic matter accumulation by increasing photosynthesis or the absorption of mineral nutrients (Ma et al., 2017). Drought and high temperature stress lead to a biomass decline through negative effects on plant growth, physiology, and reproduction (Barnabás et al., 2007). The results of our study showed that the AGB of the four plant species examined was inhibited by high temperature stress; this could be related to a variety of factors such as reduced Pn (Flexas et al., 2004) and interfered assimilate distribution (Farooq et al., 2009), resulting in a decreased biomass trend under high temperature and compound heat and drought stress, which is consistent with the results of many studies (Fahad et al., 2017; Daryanto et al., 2016). The combined drought and high temperature stress had an inhibitive effect on $O$. ochrocephalaand $S$. pulchra, while drought had a cushioning effect on the effects of the combined drought and heat stress on $K$. humilis and $P$. annua, with the temperature being dominant in the combined treatment. The BGB of O. ochrocephala and S.pulchra was the highest under the high temperature stress. The BGB of K. humilis 
and $P$. annua had a decreasing trend under the high temperature stress. Our results showed that high temperature stress was beneficial for root growth, which made plant productivity shift to an underground distribution and inhibited the BGB of plants with shallow roots. The rising temperature would lead to a decrease in the surface soil water content, making the SM condition a key factor limiting the root growth of plants with shallow roots (Yu et al., 2015).

Photosynthesis, the most important physiological and biochemical plant activity, affects material conversion and energy metabolism in plants, and it has a strong response to drought and high temperatures (Chakhchar et al., 2016; Jumrani et al., 2017). The net Pn of plants decreases under drought and high temperature stress, with the extent of the decrease varying among plants (Jing et al., 2013; Jumrani et al., 2017). Stomatal factors are the main reasons for the Pn decrease under mild water stress, while under severe water stress the chlorophyll structure damage results in a Pn decrease (Bray, 1997). The results of this study showed that the increasing drought resulted in the gradual water loss by the leaves of the four plant species, while the net $\mathrm{Pn}$ and $\mathrm{Tr}$ of the leaves also decreased. These results indicate that photosynthetic restriction factors consist mainly of stomatal restriction under drought stress and can prevent excessive water loss and ensure effective water utilization (Zhao et al., 2002). The net Pn of $K$. humilis and $P$. annua increased with the high temperature stress increase, while that of $O$. ochrocephala and $S$. pulchrainitially increased and then decreased significantly with the high temperature stress increase, which was also true for the LWC. Compared with K. humilis, P. annua, O. ochrocephala, and S.pulchra are less able to withstand high temperatures and regulate water. Under severe high temperature stress, $O$. ochrocephala and $S$. pulchra may have non-stomatal restriction and inhibit photosynthesis; this reflects the difference in the plant species' ability and manner of regulating water (Xu et al., 2013). Lawlor and Cornic (2002) found that stomatal responses are highly variable under drought conditions across plant species; the results of our study showed that the Gs differed significantly among the four plant species and did not change based on obvious rules, thereby confirming that there was not necessarily a linear relationship between Gs and drought stress.

The combined effect of drought and heat stress on plants is greater than that of a single stressor (Dreesen et al., 2012). When drought and heat stress occur simultaneously, the Gs and transpiration decrease, and heat persecution is caused by the increase of the leaf temperature (Lamaoui, et al., 2018). The results of the present study demonstrated that the promotion effect of high temperature stress on Pn did not alleviate the influence of drought stress on the photosynthetic characteristics of the four plant species, but produced a superimposed effect together with drought stress, thereby leading to a Pn decrease under combined stress. This indicates that the combined stress had a greater influence on Pn than a single stress, and the water condition played a dominant role. Rollins (2013) found that photosynthesis is not affected under drought stress, but decreases significantly under a combined drought and high temperature treatment, with temperature playing a dominant role in the combined stress; these results are significantly different from those obtained in the present study. The most plausible explanation for this outcome may be related to the characteristics of alpine meadow plants, which are more sensitive to water changes than temperature changes owing to their long-term development and survival in cold and wet environments (Xu \& Xue, 2013).

High temperature stress inhibits the Tr of O. ochrocephala and S. pulchra, and higher stomatal resistance reduces the transpiration rate after a temperature rise, thus preserving the plant moisture status (Liu et al., 2005). This was also demonstrated by the WUE analysis (Figure 5). The WUE of O. ochrocephala increased under the $\mathrm{H} 2$ treatment and that of $S$. pulchra increased significantly under the $\mathrm{H} 1$ treatment $(P$ $<0.05)$. The effects of drought were dominant in the compound stress and high temperature stress treatments as these promoted the WUE of alpine meadow plants. However, this would reduce the cooling effect of transpiration, leading to an increase in leaf temperature, especially under the combined stress of two factors, which would affect the photosynthetic capacity of the plants. The WUE of Kobresia humilis and P. annua increased significantly under the $\mathrm{H} 1$ treatment and decreased under the $\mathrm{H} 2$ treatment, showing a certain range of adaptation to high temperature stress, with the influence of high temperature being dominant in the compound stress (Figure 5). The mitigation of heat stress is achieved by a reduction in $\mathrm{Tr}$, an increase in WUE, an enhancement of photoenzyme activity, and an increase in the defense molecules of the four plant species (Blum, 2009). 
Due to the lack of continuous observation of physiological indexes of alpine meadow plants, this study could not obtain the characteristics and rules of alpine meadow species changes in small-scale time series, which had certain limitations. Therefore, in the face of the environmental effects of climate warming and frequent bouts of extreme weather, it is necessary to research the heat and drought tolerance mechanisms of alpine meadow plants with stress time and identify the genetic differences that determine their stress responses, in order to improve plant stress performance.

\section{CONCLUSION}

Drought and heat stress generally inhibited the characteristic indexes of alpine meadow plants. The effect of a single factor on height and LWC was greater than that of multiple factors combined, and the photosynthetic indexes were more sensitive to multiple factors combined than a single factor. Additionally, the response of four alpine meadow plant species to SM was more sensitive than that to DT. Moreover, our results showed that the Pn and Tr of K. humilis and $P$. annua had similar response patterns to stress; the same was true for the response patterns of the same photosynthetic characteristics of $O$. ochrocephala and $S$. pulchra . Overall, K. humilis and $P$. annuaadapted to and resisted less the stress treatment than $O$. ochrocephala and S. pulchra. The findings of this study reveal the regularities and differences in the response patterns of different functional groups of plants to environmental stress in an alpine meadow. Additionally, our results provide a theoretical basis for the rational utilization of grassland resources in alpine meadows in the context of climate change.

\section{ACKNOWLEDGMENTS}

This work was supported by the National Natural Science Foundation of China (31672475), Natural Science Foundation of Qinghai Province (2019-ZJ-908), National Key Research and Development Program of China (2016YFC0501901), and the Second Comprehensive Scientific Investigation of the Tibetan Plateau (2019QZKK0302).

\section{AUTHOR CONTRIBUTIONS}

Formal analysis, Li Ma; data curation, Zhonghua Zhang; data curation Bingrong Zhou; software, Manhou $\mathrm{Xu}$; writing-review and editing, Huakun Zhou. All authors have read and agreed to the published version of the manuscript.

\section{CONFLICT OF INTEREST}

The authors declare no conflict of interest

\section{DATA ACCESSIBILITY STATEMENT}

If the paper has a chance to be accepted, the authors will deposit their data in Dryad

\section{REFERENCES}

Ahmed, I. M., Dai, H. X., Zheng, W. T., Cao, F. B., Zhang, G. P., Sun, D. F., \& Wu, F.B. (2013). Genotypic differences in physiological characteristics in the tolerance to drought and salinity combined stress between Tibetan wild and cultivated barley. Plant Physiology and Biochemistry , 63, 49-60. https://doi.org/10.1016/j.plaphy.2012.11.004

Allen, C. D., Macalady, A. K., Chenchouni, H., Bachelet, D., Mcdowell, N., Vennetier, M., Kitzberger, T., Rigling, A., Breshears, D. D., Hogg, E. H., Gonzalez, P., Fensham, R., Zhang, Z., Castro, J., Demidova, N., Lim, J. H., Allard, G., Running, S. W., Semerci, A., \& Cobbt, N. (2010). A global overview of drought and heat-induced tree mortality reveals emerging climate change risks for forests. Forest Ecology and Management , 259(4), 660-684. https://doi.org/10.1016/j.foreco.2009.09.001

An, Y. Y. \& Liang, Z. S. (2012). Staged strategy of plants in response to drought stress. Journal of Applied Ecology , 23(10), 2907-2915. https://doi.org/10.13287/j.1001-9332.2012.0403 
Bakhshandeh, S., Corneo, P. E., Yin, L. M., \& Dijkstra, F. A. (2019). Drought and heat stress reduce yield and alter carbon rhizodeposition of different wheat genotypes. Journal of Agronomy and Crop Science, 205(2), 157-167. https://doi.org/10.1111/jac.12314

Barnabas, B., Jager, K., \& Feher, A. (2007). The effect of drought and heat stress on reproductive processes in cereals. Plant, Cell \& Environment, 31(1), 11-38. https://doi.org/10.1111/j.1365-3040.2007.01727.x

Blum, A. (2009). Effective use of water (EUW) and not water-use efficiency (WUE) is the target of crop yield improvement under drought stress. Field Crops Research , 112(2-3), 119-123. https://doi.org/10.1016/j.fcr.2009.03.009

Bray, E. A. (1997). Plant responses to water deficit. Trends in Plant Science , 2(2), 48-54. https://doi.org/10.1016/S1360-1385(97)82562-9

Chakhchar, A., Lamaoui, M., Aissam, S., Ferradous, A., Wahbi, S., Mousadik, A. E., Ibnsouda-Koraichi, S., Filali-Maltouf, A., \& Modafar, C. E. (2016). Differential physiological and antioxidative responses to drought stress and recovery among four contrasting Argania spinosa ecotypes. Journal of Plant Interactions , 11(1), 30-40. https://doi.org/10.1080/17429145.2016.1148204

Chen, H. L., Zhang, H. W., \& Xue, C.Y. (2010). Extreme climate events and agricultural meteorological services in China. Meteorological and Environmental Sciences , 33(03), 67-77. https://doi.org/10.16765/j.cnki.1673-7148.2010.03.015

Daryanto, S., Wang, L. X., \& Jacinthe, P. A. (2016). Global synthesis of drought effects on maize and wheat production. Plos One, 11(5): e0156362. https://doi.org/10.1371/journal.pone.0156362

Dreesen, F. E., De Boeck, H. J., Janssens, I. A., \& Nijs, I. (2012). Summer heat and drought extremes trigger unexpected changes in productivity of a temperate annual/biannual plant community. Environmental and Experimental Botany, 79, 21-30. https://doi.org/10.1016/j.envexpbot.2012.01.005

Du, Y. G., Ke, X., Dai, L. C., Cao, G. M., Zhou, H. K., \& Guo, X. W. (2020). Moderate grazing increased alpine meadow soils bacterial abundance and diversity index on the Tibetan Plateau. Ecology and Evolution , 1-7. https://doi.org/10.1002/ece3.6563

Fahad, S., Bajwa, A. A., Nazir, U., Anjum, S. A., Farooq, A., Zohaib, A., Sadia, S., Nasim, W., Adkins, S., Saud, S., Ihsan, M., Alharby, H., Wu, C., Wand, D., \& Huang, J. (2017). Crop production under drought and heat stress: plant responses and management options. Frontiers in Plant Science, 8, 1147. https://doi.org/10.3389/fpls.2017.01147

Farooq, M., Wahid, A., Kobayashi, N., Fujita, D., \& Basra, S. M. A. (2009). Plant drought stress: effects, mechanisms and management.Agronomy for Sustainable Development , 29(1), 185-212. https://doi.org/10.1051/agro:2008021

Field, C. B., Barros, V. R., Stocker, T. F., Qin, D., Dokken, D. J., Ebi, K. L., Mastrandrea, M. D., Mach, K. J., Plattner, G. K., Allen, S. K., Tignor, M., \& Midgley, P. (2012). Managing the risks of extreme events and disasters to advance climate change adaptation: special report of the Intergovernmental Panel on Climate Change . Cambridge, Cambridge University Press: 109-111 pp. https://doi.org/10.1017/CBO9781139177245

Flexas, J., Bota, J., Loreto, F., Cornic, G., \& Sharkey, T. D. (2004). Diffusive and metabolic limitations to photosynthesis under drought and salinity in $\mathrm{C}_{3}$ plants. Plant Biology , 6(3), 269-279. https://doi.org/10.1055/s-2004-820867

Hao, L. H., Guo, L. L., Li, R. Q., Cheng, Y., Huang, L., Zhou, H. R., Xu, M., Li, F., Zhang, X. X., \& Zheng, Y. P. (2019). Responses of photosynthesis to high temperature stress associated with changes in leaf structure and biochemistry of blueberry (Vaccinium corymbosum L.). Scientia Horticulturae , 246, 251-264. https://doi.org/10.1016/j.scienta.2018.11.007 
Huang, W. W., Zhang, N. N., Hu, T. X., Li, X. Q., He, Y. Y., \& Yin, L. (2011). Effects of high-temperature stress on physiological characteristics of leaves of Simmondsia chinensis seedlings from different provenances. Acta Ecologica Sinica , 31(23), 7047-7055. https://doi.org/CNKI:SUN:STXB.0.2011-23-009

Jing, D. W., Xing, S. J., Du, Z. Y., \& Liu, F. C. (2013). Effects of drought stress on the growth, photosynthetic characteristics, and active oxygen metabolism of poplar seedlings. Chinese Journal of Applied Ecology , 24(7), 1809-1816. https://doi.org/10.13287/j.1001-9332.2013.0420

Jumrani, K., Bhatia, V. S., \& Pandey, G. P. (2017). Impact of elevated temperatures on specific leaf weight, stomatal density, photosynthesis and chlorophyll fluorescence in soybean. Photosynthesis Research , 131(3), 333-350. https://doi.org/10.1007/s11120-016-0326-y

Keyvan, S. (2010). The effects of drought stress on yield, relative water content, proline, soluble carbohydrates and chlorophyll of bread wheat cultivars. Journal of Animal and Plant Sciences , 8(3), 1051-1060. https://doi.org/JAPS/2010/8.3/4

Lamaoui, M., Jemo, M., Datla, R., \& Bekkaoui, F. (2018). Heat and drought stresses in crops and approaches for their mitigation.Frontiers in Chemistry , 6(26). https://doi.org/10.3389/fchem.2018.00026

Lawas, L. M. F., Li, X., Erban, A., Kopka, J., Jagadish, S. V. K., Zuther, E., \& Hincha, D. K. (2019). Metabolic responses of rice cultivars with different tolerance to combined drought and heat stress under field conditions. GigaScience, 8(5), giz050. https://doi.org/10.1093/gigascience/giz050

Lawas, L. M. F., Zuther, E., Jagadish, S. V. K., \& Hincha, D. K. (2018). Molecular mechanisms of combined heat and drought stress resilience in cereals. Current Opinion in Plant Biology , 45 (Part B), 212-217. https://doi.org/10.1016/j.pbi.2018.04.002

Lawlor, D. W. \& Cornic, G. (2002). Photosynthetic carbon assimilation and associated metabolism in relation to water deficits in higher plants. Plant, Cell \& Environment, 25(2), 275-294. https://doi.org/10.1046/j.0016-8025.2001.00814.x

Li, J. L.,\& Li, X. L. (2016). Research progress on environmental adaptability of Kobresia humilis in alpine meadow.Ecological Science , 35(2), 156-165. https://doi.org/10.14108/j.cnki.1008-8873.2016.02.024

Li, X. L., Luo, L. L., Hua, Z. R. (2018). Physiological and biochemical responses of Rhododendron lapponicum to heat stress. Acta Agriculturae Boreali-Occidentalia Sinica , 27(2), 253259.https://doi.org/10.7606/j.issn.1004-1389.2018.02.013

Liu, F., Jensen, C. R., \& Andersen, M. N. (2005). A review of drought adaptation in crop plants: changes in vegetative and reproductive physiology induced by ABA-based chemical signals. Australian Journal of Agricultural Research , 56(11), 1245-1252. https://doi.org/10.1071/AR05062

Ma, L., Xu, M. H., Zhai, D. T., Jia, Y. Y. (2017). Response of alpine meadow vegetation-soil system to climate change: A review. Chinese Journal of Ecology, 36(6), 1708-1717. https://doi.org/10.13292/j.10004890.201706 .009

Mahalingam, R. (2015). Consideration of combined stress: A crucial paradigm for improving multiple stress tolerance in plants.Combined Stresses in Plants , 1-25. https://doi.org/10.1007/978-3-319-07899-1_1

Nankishore, A. \& Farrell, A. D. (2016). The response of contrasting tomato genotypes to combined heat and drought stress. Journal of Plant Physiology , 202, 75-82. https://doi.org/10.1016/j.jplph.2016.07.006

Pachauri, R. K., Allen, M. R., Barros, V. R., Broome, J., Cramer, W., Christ, R., Church, J. A., Clarke, L., Dahe, Q., Dasgupta, P., \& Dubash, N. K. (2014) Climate Change 2014: Synthesis Report. Contribution of Working Groups I, II and III to the Fifth Assessment Report of the Intergovernmental Panel on Climate Change (p. 151). Geneva, IPCC.

Pradhan, G. P., Prasad, P. V., Fritz, A. K., Kirkham, M. B., \& Gill, B. S. (2012). Effects of drought and high temperature stress on synthetic hexaploid wheat. Functional Plant Biology , 39(3), 190-198. 
https://doi.org/10.1071/FP11245

Prasad, P. V. V., Pisipati, S. R., Momčilović, I., \& Ristic, Z. (2011). Independent and combined effects of high temperature and drought stress during grain filling on plant yield and chloroplast EF-Tu expression in spring wheat. Journal of Agronomy \&3 Crop Science , 197(6), 430-441. https://doi.org/10.1111/j.1439037X.2011.00477.x

Peñuelas, J., Sardans, J., Estiarte, M., Ogaya, R., Carnicer, J., Coll, M., Barbeta, A., Rivas-Ubach, A., Llusia, J., Garbulsky, M., Filella, I., \& Jump, A. S. (2013). Evidence of current impact of climate change on life: a walk from genes to the biosphere. Global Change Biology , 19(8), 2303-2338. https://doi.org/10.1111/gcb.12143

Qaseem, M. F., Qureshi, R., \& Shaheen, H. (2019). Effects of pre-anthesis drought, heat and their combination on the growth, yield and physiology of diverse wheat (Triticum aestivum L.) genotypes varying in sensitivity to heat and drought stress. Scientific Reports , 9, 6955. https://doi.org/10.1038/s41598-019-43477-z

Read, Q. D., Moorhead, L. C., Swenson, N. G., Bailey, J. K., \& Sanders, N. J. (2014). Convergent effects of elevation on functional leaf traits within and among species. Functional Ecology , 28(1), 37-45. https://doi.org/10.1111/1365-2435.12162

Ren, F., Yang, X. X., Zhou, H. K., Yao, B. Q., Wang, W. Y., Wen, J., He, J., \& Zhao, X. Q. (2013). Physiological-biochemical responses of three plant species to experimental warming using OTC in alpine meadow on Qinghai-Tibetan Plateau. Acta Botanica Boreali-Occidentalia Sinica , 33(11), 2257-2264. http://210.75.249.4/handle/363003/3872

Rollins, J. A., Habte, E., Templer, S. E., Colby, T., Schmidt, J., \& von Korff, M. (2013). Leaf proteome alterations in the context of physiological and morphological responses to drought and heat stress in barley (Hordeum vulgare L.). Journal of Experimental Botany , 64(11), 3201-3212. https://doi.org/10.1093/jxb/ert158

Salvucci, M. E. \& Crafts-Brandner, S. J. (2004). Inhibition of photosynthesis by heat stress: the activation state of Rubisco as a limiting factor in photosynthesis. Physiologia Plantarum , 120(2), 179-186. https://doi.org/10.1111/j.0031-9317.2004.0173.x

Sehgal, A., Sita, K., Bhandari, K., Kumar, S., Kumar, J., Prasad, P. V., Siddique, K. H. M., \& Nayyar, H. (2019). Influence of drought and heat stress, applied independently or in combination during seed development, on qualitative and quantitative aspects of seeds of lentil (Lens culinaris Medikus ) genotypes, differing in drought sensitivity.Plant Cell $\&$ Environment , 42(1), 198-211. https://doi.org/10.1111/pce.13328

Seki, M., Umezawa, T., Urano, K., \& Shinozaki, K. (2007). Regulatory metabolic networks in drought stress responses. Current Opinion in Plant Biology , 10(3), 296-302. https://doi.org/10.1016/j.pbi.2007.04.014

Sita, K., Sehgal, A., Kumar, J., Kumar, S., Singh, S., Siddique, K. H. M., \& Nayyar, H. (2017). Identification of high-temperature tolerant lentil (Lens culinaris Medik.) genotypes through leaf and pollen traits.Frontiers in Plant Science , 8, 744. https://doi.org/10.3389/fpls.2017.00744

Song, Y. L., Wang, K. Q., Wang, S., Qian, X. J., \& Xu, J. (2018). Physiological responses of three kinds of cool season turfgrasses under continuous drought stress, heat stress and their interaction. Acta Agrestia Sinica , 26(3), 705-717. https://doi.org/10.11733/j.issn.1007-0435.2018.03.025

Xu, Z., Shimizu, H., Yagasaki, Y., Ito, S., Zheng, Y., \& Zhou, G. (2013). Interactive effects of elevated $\mathrm{CO}_{2}$, drought, and warming on plants. Journal of Plant Growth Regulation , 32(4), 692-707. https://doi.org/10.1007/s00344-013-9337-5

Xu, M. H. \& Xue, X. (2013). Correlation among vegetation characteristics, temperature and moisture of alpine meadow in the Qinghai-Tibetan Plateau. Acta Ecologica Sinica , 33(10), 3158-3168. https://doi.org/10.5846/stxb201202140190 
Xue, L., Zhang, R., Xi, R. C., Guo, S. H., Yang, Z. Y., Liu, B., \& Wei, R. P. (2012). Seasonal change of leaf morphological traits of six broadleaf seedlings in South China. Acta Ecologica Sinica , 32(1), 123-134. https://doi.org/10.5846/stxb201011291691

Yu, X. C., Yao, B. Q., Zhou, H. K., Jin, Y. X., Yang, Y. J., Wang, W. Y., Dong, S. K., \& Zhao, X. Q. (2015). Variable responses to long-term simulated warming of underground biomass and carbon allocations of two alpine meadows on the Qinghai-Tibet Plateau. ChineseScience Bulletin , 60(4), 379-388. https://doi.org/10.1360/N972014-00473

Zandalinas, S. I., Mittler, R., Balfagón, D., Arbona, V., \& Gomez-Cadenas, A. (2017). Plant adaptations to the combination of drought and high temperatures. Physiologia Plantarum , 162(1), 2-12. https://doi.org/10.1111/ppl.12540

Zhang, L. R., Niu, H. S., Wang, S. P., Li, Y. N., \& Zhao, X. Q. (2010). Effects of temperature increase and grazing on stomatal density and length of four alpine Kobresia meadow species, Qinghai-Tibetan Plateau.Acta Ecologica Sinica , 30(24), 6961-6969. https://doi.org/CNKI:SUN:STXB.0.2010-24-032

Zhang, W. L., Zhu, G., Huang, W. G., Zhang, Y., Wang, L., Luo, X. L., \& Liu, Y. B. (2020). Physiological response characteristics ofHedysarum multijugum, Clematis fruticosa and Buddleja alternifolia seedlings to drought in semi-arid region of Northwest China. Journal of Desert Research , 40(3), 159-167. https://doi.org/10.7522/j.issn.1000-694X.2019.00065

Zhao, C. M. \& Wang, G. X. (2002). Effects of drought stress on the photoprotection in Ammopiptanthus mongolicus leaves. Acta Botanica Sinica , 44(11), 1309-1313.

Zhao, Y. Y., Zhou, H. K., Yao, B. Q., Wang, W. Y., Dong, S. K., \& Zhao, X. Q. (2015). The influence of long-term simulating warming to the plant community and soil nutrient of alpine meadow. Acta Agrestia Sinica , 2015, 23(4), 665-671. https://doi.org/10.11733/j.issn.1007-0435.2015.04.001

\section{Hosted file}

Tables and figures.docx available at https://authorea.com/users/355902/articles/478981drought-heat-and-their-combined-stress-reduce-the-productivity-and-alter-thephotosynthetic-characteristics-of-different-alpine-meadow-plants 